\title{
BECOMING A SURGICAL LEADER
}

\author{
Lawrence H. Cohn, MD
}

l eadership is taking responsibility to direct the Lactions of others in carrying out the purposes of an organization, with accountability for both success and failure. Leadership is trying to be the best you can be, while at the same time being a role model for those around you. Leadership is the ability to make timely decisions and to care about those who work for you and with you. In his provocative book, "Leadership Secrets of Attila the Hun," author Wes Roberts states, "To be a good leader, you must have a passion to succeed and this passion drives you to prepare yourself and your colleagues to excel...excel by actions not words, so to establish the morale and integrity of subordinates aided by that ever constant requirement, the ability to make good decisions."

This article will depart from the tradition topics (discussing the use of quantitative data related to a procedure, treatment, or laboratory experiment) by focusing on qualitative and subjective aspects of our profession. It will focus on what it takes to reach goals of performance to attain leadership positions in surgery.

A number of great industrial leaders have written and spoken about leadership, which has relevance to academic surgery. Two excellent examples are Jack Welch, CEO of General Electric, the world's largest corporation, and Andy Grove, 1 of the founders of Intel Corporation. In the world of sports management, Mark McCormick has also brought leadership skills to the management of some of the best paid athletic performers of our time. Among military leaders, General Colin Powell stands out for his recent exemplary leadership career in the Army. All of these individuals have been remarkable leaders in their own fields and have lessons for us in academic medicine and surgery. From their writings I have distilled basically 3 types of leaders: (1) those who make things happen, (2) those who watch things happen, and (3) those who wonder what

From the Harvard Medical School and the Division of Cardiac Surgery, Brigham and Women's Hospital, Boston, Mass.

Address for reprints: Lawrence H. Cohn, MD, Brigham and Women's Hospital, 75 Francis St, Boston, MA 02115.

J Thorac Cardiovasc Surg 2000;119:S42-4.

Copyright $@ 2000$ by The American Association for Thoracic Surgery.

0022-5223/2000 $\$ 12.00+0 \quad \mathbf{1 2 / 0 / 1 0 4 7 2 6}$

doi: $10.1067 / \mathrm{mtc} .2000 .104726$ happened. Underlying all leadership success is a passion for excellence in the chosen field of endeavor that drives the leader who drives the organization, regardless of his or her business or profession. This passion for excellence sets both the tone of the organization and the goal of the organization and the leadership.

Surgeons make excellent leaders because of the complex logistics of operations that they must organize virtually every day and the requirement for decisiveness in every operation. There are many thoracic surgeons who have demonstrated superb leadership skills while managing major medical centers, serving as leaders of national organizations, and even serving in high government offices as elected officials. So it is natural for surgeons to seek leadership roles in whatever endeavors they undertake.

\section{Starting out}

How does one go from a brand new assistant professorship in cardiothoracic surgery to a division or department chief, and with some luck, perhaps even president of some of the world's great surgical organizations, such as the American Association of Thoracic Surgeons?

As an assistant professor starting out in academic medicine, 1 of your basic tenets should be the immediate understanding that an academic surgeon must gain credibility locally and nationally by documenting experiences and communicating them through writing and lecturing, particularly in peer-reviewed journals or national meetings. Your ability to become a successful "player" in this area will depend on your dedication to the documentation of scholarship in peer-reviewed surgical literature in laboratory research and/or clinical research areas. This indicates to the surgical academic world that this individual is dedicated to academics.

The writing of papers may include your own personal laboratory research or may begin with a retrospective analysis (that your institution has not presented or published) of a series of interesting patients. There is interesting and important information to be learned from almost every collected clinical series in every institution if analyzed correctly, and this can be communicated clearly and concisely. An individual interested in academic surgery should want to give lectures and speeches and accept invitations to do so. Such an individual should be available for local referral hospital rounds or 
regional meetings of the American College of Surgeons, the Society of Thoracic Surgery, the American College of Cardiology, or the American College of Chest Physicians. This could include hospital grand rounds, nursing in-service education, discussions at local hospitals or regional medical centers, and of course, national meetings whenever possible. These exercises improve your public speaking skills and allow your name to become known as someone willing to participate in a wide range of educational forums, an important leadership quality.

Admission to various surgical and medical societies in our specialty should be accomplished as quickly as possible. This helps to demonstrate your interest in the organizational structure of the specialty. An early entrance into the candidates' group of the Society of Thoracic Surgery, American Heart Association, or American College of Cardiology is important. These are all excellent organizations and provide you the ability to network with colleagues at all levels in many different venues. Networking is extremely important in any large organization and is especially important if individuals wish to increase experience in a particular group. A group that enters societies together after finishing a residency will often find themselves interacting a great deal throughout their careers in a wide variety of topics and venues. Many individuals who entered organizations in my "class" are now close colleagues and friends who depend on each other in a variety of ways. We feel free to call on each other to help out on projects or to complete a roster on an important educational mission.

It is oftentimes helpful to seek a societal mentor in an important organization such as the American Association of Thoracic Surgeons or the Society of Thoracic Surgeons, someone who is a friend, colleague, or mentor at your institution or someone you have known in training. A mentor can educate you about an organization and increase your participation. One of the major requirements for all of these activities is to make the time available. This will require a fairly delicate balancing act between work, family, outside interests, and organizational activities.

\section{Toward your goal}

As you mature and gain more experience, you will be given greater opportunities to work within organizational frameworks. As you receive assignments within societies, do the homework completely and get the job done efficiently. In my opinion, it is extremely poor form for individuals who claim interest in an organization to volunteer for certain assignments and then to "drop the ball," relying on others to carry the burden. If repeated, this pattern reflects poorly on an individual and will prevent that individual from ever achieving stature within an organization.

Attending national meetings is important. You can always find excuses for not going (such as, the weather is bad, I have 2 extra cases to do, I don't feel like it), but I firmly believe the old adage of my colleague Bruce Lytle of Cleveland: "Half of life is just showing up." You should not underestimate the importance of having people see you and become convinced of your sincere interest in promoting a society's academic affairs.

Interfacing with medical colleagues in an individual specialty is also important. For example, the American College of Cardiology, provides ample opportunity for cardiac surgeons to interface with cardiologists, and similar opportunities abound for pulmonary/ esophageal surgeons to interface similarly at the American College of Chest Physicians with pulmonologists. These combined medical/surgical meetings represent valuable forums for learning what is going on in the management of diseases in a particular specialty from the combined medical and surgical point of view. Continued exposure at medical/surgical meetings promotes more credibility when talking to medical colleagues and can help to insure your insights into the meaningful strategies for best treatment. In turn, by building such bridges, medical colleagues will begin to rely on your judgment in many surgical matters. You will often be called on to lecture and to conduct a variety of discussions at local and national meetings. Although participation in organizations is key to developing a leadership role, do not make the mistake of spreading yourself too thin. It is far better to focus your energies rather than be perceived as striking about for any port in a storm. It is also important to attend the ceremonial and business functions of an organization on a fairly regular basis. This again demonstrates sincere interest and sends signals to the leadership that you can be depended on for day-to-day, month-to-month detail work that is so necessary for running a well-managed and effective organization.

\section{Nearing the top}

After a number of years of working on committees and performing the necessary "trench work," you will realize that you know colleagues with similar interests throughout the country and the world. Should you wish to move on and up, you are now positioned to work toward a leadership position in a surgical organization.

First and foremost, be willing to assume responsibility for projects that are important to your specialty or your division that may require a significant amount of extra work. An example is interfacing with government 
and industrial representatives about policy matters or financial sponsorship for a societal project. Other major area efforts could involve postgraduate educational programs, participation in thoracic surgical work force programs, or work in the increasingly important new area of information systems and data retrieval. The homework that is required when you take on such a responsibility is important, and an organization will be most appreciative of a job well done, whether in the hospital or with a national organization.

Working closely with an organizational staff can be of help in the process of committee projects. This collaboration will expedite your learning timelines and provide guidelines for how best to get things done. Administrators in the American Association of Thoracic Surgeons or Society of Thoracic Surgeons, for example, can bring to bear important services that allow you to do your assignment more efficiently. As you gain more experience and more seniority, there are more demands on your time; this help can be of great importance. If projects are to be completed, they will often require travel. So that you can be well-informed, you will also need to be available for conference calls or video conferences. You may need to rearrange operating room responsibilities or other elective clinical matters to fulfill these obligations. The opportunity to do projects with increased responsibility depends on a number of factors, but certainly your demonstrated willingness to work and to the homework and overall enthusiasm are important in moving toward surgical leadership.

\section{Conclusion}

In the end, several items for leadership are important, regardless of the organization you serve. These qualities include having charisma, honesty, and integrity, being a role model, being able to make timely decisions, and taking care of people in the organization, whether it be your own division, national, or international committee that is dedicated to thoracic surgery. To be a good surgical leader, you must be a good communicator. You must also continue to be the best surgeon you can be because surgeons highly respect surgeons who do surgery. Budget your time so that you have time slots available for national and regional organizations and yet leave time for your increasing clinical practice and family. Remember to be a team player; do not surprise your boss. Always keep your boss involved and knowledgeable about your activities. Do not surprise your national committee chairperson with information that may look good in a committee meeting but that may surprise or put off the chairperson of that committee; communicate critical information before an open meeting. Things will move forward far more effectively if everybody is on "the same page" related to the responsibility chain.

In summary, principles of leadership are important in all surgical organizations whether it be a division or a national organization. Making the time, making the effort, and doing the work in a charismatic, cooperative way are key steps to becoming a surgical leader. 